\title{
A MORTE E O "EU": POESIA E OUTRAS ARTES NO ÚLTIMO HERBERTO HELDER ${ }^{1}$
}

\author{
DEATH AND THE "I": POETRY AND OTHER \\ ARTS IN THE LATER HERBERTO HELDER
}

Fernando Velasco ${ }^{2}$

\section{RESUMO}

Os últimos livros de Herberto Helder contêm inflexões significativas em relação ao conjunto de sua obra. No cerne das mudanças, está a renovação das formas de uma noção desde sempre central para a escrita do poeta: a de morte. O último Herberto Helder, então, se abre ao convívio entre diferentes ideias de morte, às quais correspondem diferentes regimes da poesia. Neste sentido, a interação entre diferentes regimes da morte afeta, por um lado, os regimes da autoria, as concepções do "eu" e o pacto de leitura propostos pelo poema e, por outro, as relações que a escrita mantém com duas noções que a estruturam: as de tempo e de imagem. O conceito de "estilo tardio", desenvolvido por Theodor Adorno e, depois, por Edward Said, se oferece como instrumento de análise das articulações entre morte, tempo e imagem nos momentos finais da poesia de Herberto Helder, interrogadas a partir das relações que estabelece ou permite estabelecer com a música, o cinema e a fotografia.

PALAVRAS-CHAVE: Herberto Helder, morte, estilo tardio

\section{ABSTRACT}

The last books by Herberto Helder have significant inflections in relation to his whole work. The core of these changes is the renewal of the forms of an always central notion to the poet's writing: the one of death. The later Herberto Helder opens itself to the coexistence of different ideas of death, to which correspond different regimes of poetry. In this sense, the interaction between different regimes of death affects, on the one hand, the regime 
of authorship, the conceptions of the "I" and the reading pact proposed by the poem, and, on the other hand, the relations that the writing keeps with two notions that structure it: the ones of time and image. The concept of "late style", developed by Theodor Adorno and then by Edward Said, offers itself as a tool of analysis of the links between death, time and image in the final moments of Herberto Helder's poetry. The relations that it establishes or allows to establish with music, cinema and photography are the point of departure to its questioning.

KEYWORDS: Herberto Helder, death, late style

\section{APRESENTAÇÃO DOS TEMAS ${ }^{3}$}

Este ensaio propõe algumas reflexões sobre o último Herberto Helder. Ou ainda menos: um pequeno número de ideias relacionadas aos momentos finais da escrita do poeta. Por "último Herberto Helder" ou "momentos finais da escrita do poeta", me refiro a seus cinco últimos livros de poesia: A Faca Não Corta o Fogo (2008), Servidões (2013), A Morte Sem Mestre (2014), Poemas Canhotos (2015) e Letra Aberta (2016). Serão quase sempre deles os poucos poemas e excertos de poemas convocados durante este ensaio.

Assumo uma premissa: não apenas há no último Herberto Helder inflexões significativas em relação ao conjunto de sua obra, como no cerne destas inflexões está a morte. Ou ainda: uma renovação dos sentidos, das formas da morte.

Antecipo também uma hipótese: as novas formas da morte, ou melhor, a interação entre diferentes regimes da morte, afeta as relações que os momentos finais da escrita do poeta mantêm com os temas do tempo e da imagem.

Comecemos pela morte.

\section{DEPOIS DA MORTE}

A morte sempre esteve na escrita de Herberto Helder, em muitos sentidos e de muitas formas. Por enquanto, atenho-me a apenas uma. Lembremos um pouco do que já foi dito sobre ela.

Para Silvina Rodrigues Lopes (2003, p. 10), a “morte", uma certa ideia de morte, conforma, em Herberto Helder, uma poética segundo a qual "o poeta se sela hermeticamente no poema em que se escreve, dispersando-se, sendo aquilo que se torna”. Um devir-escrita, um tornar-se poema que, para Manuel Gusmão, "devolve à vida aquele que [...] antes tinha morrido. Um momento antes do poema 'era a morte'. Ou, ainda: o poema é sempre 'depois da morte"' (2010, p. 386). 
Em Herberto Helder, a escrita é, portanto, um movimento contínuo de "morte" e "ressurreição". Isto é: de anulação do corpo que escreve enquanto realidade empírica, por um lado, e inscrição de sua singularidade no poema, por outro. Neste sentido, estamos, em Herberto Helder, diante "de uma subjectividade ao mesmo tempo solvente e expansiva" (Martelo, 2009 , p. 153), a que corresponde, se quisermos, um poema "simultaneamente [...] interior e exterior" (id., 2018, p. 2).

"Exterior" porque, no contexto das poéticas de tradição moderna, o poema, em Herberto Helder, se identifica com sua própria exterioridade. Quer dizer: não se deixa penetrar pelo que está antes ou fora dele mesmo e, desta forma, não reconhece autoridade, por exemplo, à história ou à biografia de quem escreve. Inversamente: o poema se afirma em sua autonomia.

"Interior", a escrita, em Herberto Helder, pode ser de mais de uma maneira. Entre elas, a de que é um gesto de transformação de uma memória pessoal na medida em que "entra pelos olhos" (Helder, 2017a, p. 138) - um acervo particular de imagens, recortes de realidade, fatias de mundo - em forma poética, matéria poemática. O poema recria poeticamente as imagens com que se monta a si mesmo, ao mesmo tempo que divide com o mundo a matéria de que se cria a si próprio.

Mas o poema é "interior" também porque "nasce directamente do corpo" (Helder, 2017a, p.129), como um "nó corpo-linguagem" (Lopes, 2003 , p. 34). Ou, se preferirmos: como "um entrar num ritmo" (ibid., p. 33), "presentificação do ritmo do corpo que escreve" (Martelo, 2018, p. 3). A escrita faz então circular, entre o corpo e o texto, "uma energia rítmica sem quebra" (Helder, 2017a, p. 135); estabelece, entre o corpo que escreve e a matéria de que se inventa, um "princípio de continuidade energética" (ibid.), pelo qual "o sujeito participa do cosmos" (Helder, 1964, s/p). Outra maneira de dizer: poema, poeta e mundo formam uma unidade rítmica.

Voltarei ao tema do ritmo. Antes disto, retornemos ao da morte.

\section{ANTES DA MORTE}

A morte, isto é, a ideia de morte de que depende a escrita do poeta em poema - e, portanto, a unidade rítmica entre eles e o mundo - não coincide com a de uma morte literal, biológica, biográfica - a morte de que morreremos todos. E, no entanto, no último Herberto Helder, será esta morte a olhar de fora do poema para dentro dele. Um poema de Servidões (2013) mostra-a claramente (Helder, 2017, p. 681):

\footnotetext{
os capítulos maiores de minha vida, suas músicas e palavras, esqueci-os todos:

octagenário apenas, e a morte só de pensá-la calo e é claro que a olhei de frente no capítulo vigésimo mas não nunca nem jamais agora agora sou olhado, e estremeço do incrível natural de ser olhado assim por ela
} 
O poema que era "depois da morte" passa a estar também antes dela. A morte com que o poeta se escreve passa a conviver com a morte sobre a qual escreve. A "morte" de que depende a projeção de um autor textual passa a negociar com a que espreita um autor presumivelmente empírico. Ao colocar diferentes regimes da morte em interação, o poema permite então perceber tanto "a impossibilidade de fazermos coincidir autor textual e autor empírico" (Buescu, 1998, p. 25), quanto "a existência de elos e relações entre ambos" (ibid.). Mais concretamente: octagenário e sob os olhares da própria morte, o poeta que o poema escreve - ou, se preferirmos, o poeta que se escreve em poema - permite perceber, ainda que não permita apreender ou cristalizar, algo sobre o poeta que escreve o poema, nos exatos oitenta e dois anos que conta quando da publicação de Servidões (2013).

Assim é que a escrita de Herberto Helder, de rigorosamente autônoma, se permite, em seus momentos finais, penetrar por biografemas. $\mathrm{O}$ poema, outrora realidade absoluta de si mesmo, não só se abre a irrupções fragmentárias do que existe antes e fora dele próprio, como autoriza remissões, confere certa autoridade, a algo do que é anterior e exterior a ele: a perspectiva de uma morte biográfica. Ou antes: autobiográfica: "morte própria”, como a que nomeia o último fragmento de Photomaton \& Vox (1979), ou como a que faz de "toute auto-bio-graphie [...] une auto-bio-thanato-graphie”, segundo Louis Marin (1991, p. 118).

Portanto, se não permite entender imediata ou totalmente os últimos livros de Herberto Helder como autobiografias, a interação entre diferentes formas da morte, introduz, nos momentos finais da escrita do poeta, elementos a que se pode tomar plausivelmente como autobiográficos. Neste sentido, ao transformarem a natureza da instância autoral para que apontam, ou de modo mais amplo, ao renovarem os regimes da autoria afirmados pelo último Herberto Helder, as novas formas da morte deslocam o pacto de leitura que sua poesia propõe.

Mas os deslocamentos do pacto de leitura proposto pelos momentos finais da poesia de Herberto Helder, o reforço daquilo que os torna mais evidentemente uma escrita de si e as metamorfoses do "eu" projetado pelo poema estão entre as expressões mais visíveis de inflexões que todavia as ultrapassam. Ou seja: o que a interação entre diferentes regimes da morte afeta é, na realidade, o funcionamento global da escrita do poeta. Nesta perspectiva, transformam-se, designadamente, as relações que a ideia de morte mantém com outras duas noções que estruturam desde sempre a poética de Herberto Helder e com as quais interage de modo constante: as noções de tempo e de imagem.

Para investigar as articulações entre as ideias de morte, tempo e imagem no último Herberto Helder, recorramos ao conceito de "estilo tardio", tal como desenvolvido por Theodor Adorno e, depois, por Edward Said. 


\section{ESTILO TARDIO}

"Acho que apesar de tudo escrevi um poema aceitável", escreve Herberto Helder (2016, p. 23), em Letra Aberta (2016), como se apenas minimamente satisfeito em relação à sua obra. Antes disto, nos Poemas $\mathrm{Ca}$ nhotos (2015), o poeta indicava não este contentamento limitado, mas um flagrante desencontro, um estado de anomalia diante de sua poesia: "em boa verdade houve um tempo em que tive uma / ou duas artes poéticas, / agora não tenho nada" (Helder 2015, p. 18-19), escreve, como se distante dos princípios de sua escrita, exilado dos fundamentos de sua criação.

Os signos do "exílio", do "distanciamento" e da "anomalia" são próprios ao "estilo tardio". Para Adorno e Said, o "estilo tardio" não se refere meramente ao que é "feito por último" ou "em idade avançada" e sim àquilo que emerge quando o artista dá à intensificação da consciência de sua própria morte a forma de "um novo idioma para sua arte e pensamento" (Said, 2009, p. 26), um novo idioma estético, em que se pronuncia não uma maturidade exultante ou satisfeita, mas irreconciliada consigo mesma, "despida de harmonia ou serenidade" (ibid., p. 27).

Talvez sejam assim os momentos finais da poesia de Herberto Helder, no sentido de que é neles constante a presença de um '“eu' que escreve num furor exasperado, doloroso ou mesmo aflito" (Martelo, 2013, p. 9), sempre irredutível em sua disposição de corresponder aos olhares que recebe da morte. Talvez os últimos livros do poeta estejam escritos em idioma tardio.

\section{TEMPOS MUSICAIS}

Mas não apenas como um idioma tardio podem ser descritas as inflexões finais da poesia de Herberto Helder. Para Manuel de Freitas, elas correspondem a um novo arranjo, um novo tom, mais “[á]spero, rude, violento" (Freitas, 2013, p. 41) e, por isto mesmo, "mais conforme (embora inconformado) ao tempo bárbaro e concreto em que vivemos" (ibid.).

Ou seja: em seus arranjos tardios, a escrita do poeta se acercaria de seu próprio tempo, tenderia à sua própria atualidade. Nela passariam então a conviver, por um lado, uma "música arrebatada e quase intemporal” (Freitas, 2013, p. 35) e, por outro, uma “'fala cantante', mais rente à linguagem dita comum e ao mundo, num sentido histórico e já não exultantemente atemporal" (ibid., p. 38).

Ora atemporal, ora inserida no tempo histórico, a poesia tardia de Herberto Helder soaria, então, antes de tudo inatual, intempestiva, extemporânea, como soaram extemporâneas, intempestivas e inatuais as músicas tardias de artistas como Beethoven e Richard Strauss, segundo Adorno e Said. Mas se o anacronismo do Beethoven e do Strauss tardios tem a forma de uma "regressão do agora ao outrora" (Said, 2009, p. 43), o do último Herberto Helder corresponde à passagem de um outrora absoluto, um sempre hora nenhuma, a um agora histórico, cronológico: um anacronismo orientado para o presente. 


\section{TEMPOS DA MORTE}

Vejamos então alguns excertos de um poema de A Morte Sem Mestre (2014). Já em seu trecho inicial, Herberto Helder (2017, p. 694) se refere à capacidade da poesia de resistir à morte da língua em que é concebida e atravessar assim o tempo:

tão fortes eram que sobreviveram à língua morta, esses poucos poemas acerca do que hoje me atormenta, décadas, séculos, milénios, e eles vibram

No entanto, apenas algumas linhas à frente, a morte é também o que situa a escrita no mais cotidiano e, por isto mesmo, cronológico dos tempos:

e entre os objectos técnicos no apartamento, rádio, tv, telemóvel,

relógios de pulso,

esmagam-me por assim dizer com a sua verdade última

sobre a morte do corpo

Mas a perspectiva da morte do corpo, da morte biológica, biográfica, não impede que o poema termine por afirmar seu pendor para a eternidade:

entre o poema sumério e este poema de curto fôlego, mas que talvez respire um dia, ou dois, ou três dias mais:

[...]

tudo isso perdura em mim pelos milénios fora, disso, oh sim, é que eu estou vivo e estremeço ainda

Ao abrigar mais de uma ideia de morte, o poema se insere em mais de um tempo. Se preferirmos: na poesia tardia de Herberto Helder, diferentes regimes da morte correspondem a diferentes regimes do tempo.

\section{DO CINEMA À FOTOGRAFIA}

O "estilo tardio", de fato, não é senão algo que estabelece correspondências ou cria articulações entre a intensificação da consciência da morte e a transformação das relações entre a arte e o tempo. Mas o "tardio" não é só isso: é também o que associa a transformação das relações entre a arte e o tempo às metamorfoses da matéria, da espacialidade artística: Cito Said (2009, p. 12): “conversão do tempo em espaço: transformação da sequência cronológica em paisagem, de modo que se torne possível ver, vivenciar, capturar e trabalhar o tempo".

A noção de "estilo tardio" nos conduz assim ao cerne da poética Herberto Helder: "[q]ualquer poema é um filme, e o único elemento que importa é o tempo, e o espaço é a metáfora do tempo" (Helder, 2017a, p. 140). Quer dizer: ao poema importa mostrar o tempo, o próprio tempo, um tempo não-cronológico, mas absoluto, e para isso precisa transformá-lo em espaço, paisagem, imagem. Ou melhor: em uma sequência de ima- 
gens poéticas, agenciadas como se montadas cinematograficamente: "uma espécie de cinema das palavras" (id., 2017, p. 272).

A poesia, em Herberto Helder, se concebe, portanto, como um tipo de cinema. Mas tomemos outro poema de Servidões (2013), a que é atribuída a data do aniversário de oitenta anos do poeta (Helder, 2017, p. 609):

saio hoje ao mundo, cordão de sangue à volta do pescoço, e tão sôfrego e delicado e furioso, de um lado ou de outro para sempre num sufoco, iminente para sempre

\section{XI.2010: 80 ANOS}

Parto e enforcamento, vir-a-ser e não-ser-mais, tocam-se em um presente rigorosamente demarcado, extraído ao calendário. $\mathrm{O}$ nascimento, origem tensionada para a extinção, não é senão um passado em que se aninha o futuro que lhe corresponde: a morte. O poema é assim o retrato de um instante suspenso do contínuo do tempo, em que se adensam presente, passado e futuro: uma fotografia.

\section{PARAGEM, PREFIGURAÇÃO}

Para Walter Benjamin, a fotografia é mesmo isso: a forma por excelência "da imagem dialética capaz de contrair presente, passado e futuro em um momento singular" (Lissovsky, 2014, p. 7). Por isto, é também "o paradigma do acontecimento histórico" (ibid.). Ou ainda: as fotografias são como "'pausas do destino': oportunidades de suspensão do fluxo temporal que nos permitem acessar o âmago da experiência da história no que ela tem de inextricavelmente próprio e pessoal" (ibid.).

Para Herberto Helder, é também assim: a fotografia é uma "coisa mítica, cuja inquietante proposta é parar o tempo num pequeno espaço e garantir-lhe uma ambição de eternidade" (Helder, 2018, p. 104). Neste sentido, é como "um lapso da 'história' [...], acabado de nascer e já voltado às várias mortes das coisas todas" (ibid.). Algo cuja vocação é encontrar na história brechas em que o próprio tempo se mostre como imagem, insinuar no tempo histórico o tempo da morte, mostrar em suas falhas as imagens de uma morte por vir.

Em suma: paragem e prefiguração.

\section{RETRATO DO ARTISTA}

Que a fotografia estabelece elos entre as ideias de paragem do tempo e prefiguração da morte, sabemos desde Roland Barthes: ao garantir a realidade do que fixa, como se disposta a legar o presente à sua eternidade impossível, ela é sempre uma imagem da certeza última da morte. Se quisermos: a fotografia "diz a morte no futuro" (Barthes, 1989, p. 142), é sempre "um signo imperioso de [...] morte futura" (ibid., p. 144), "uma catástrofe que já ocorreu” (ibid.). 
Vejamos, então, uma fotografia de Herberto Helder, incluída nas edições oficiais de Poemas Canhotos (2015) e Letra Aberta (2016), os últimos livros de sua obra poética:

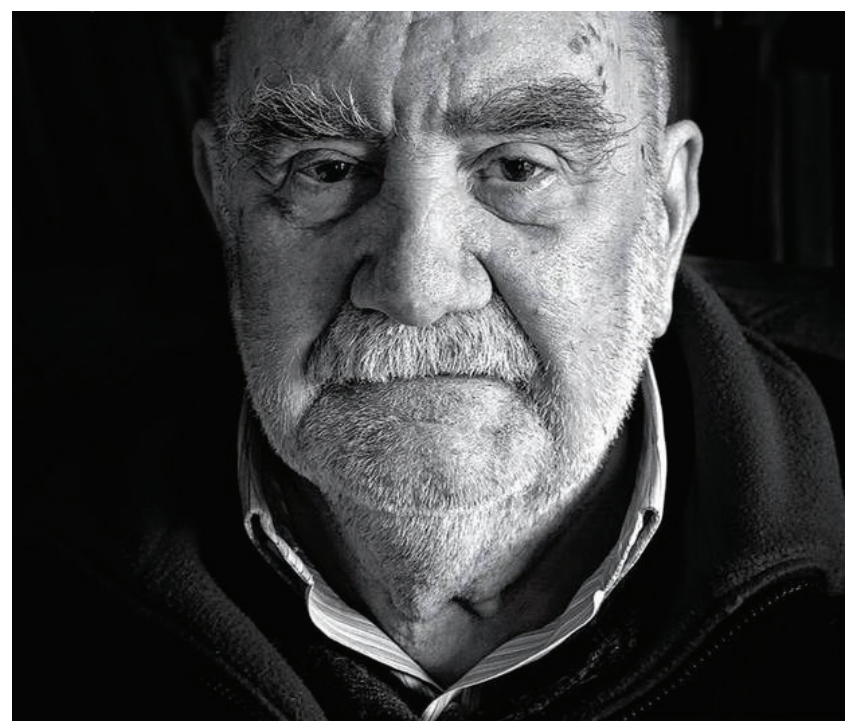

(Herberto Helder, aos 84 anos. Foto: Alfredo Cunha, fevereiro de 2015)

O poeta olha para a câmera. Sobrancelhas em desalinho, bigode irregular, barba por fazer, camisa listrada e jaqueta esportiva, aguarda o clique. Não é, claro, a primeira vez que se permite fotografar. Mas tampouco era este um hábito seu - menos por uma qualquer excentricidade do que pelo compromisso com um projeto poético para o qual a apresentação do rosto do poeta é antes de tudo (des)figuração da escrita, figura de linguagem, prosopopeia. Por que então a foto, esta exata foto?

Talvez Adorno e suas reflexões sobre o "estilo tardio" possam fornecer novamente algumas pistas. Para o filósofo, a condição tardia implica a perda da "totalidade da experiência artística" (Serra, 2018, s/p), pela qual "a auto-referência de um indivíduo [...] autodeterminado, se torna um mito" (ibid.). Nesta perspectiva, o "estilo tardio" é como um desprender de lascas do que antes era um todo. Por isto, afirma Adorno, é sempre a "expressão da índole mítica da criatura e da sua queda, [...] simbolicamente, por assim dizer, em instantes de detenção" (apud. Serra, 2018, s/p).

Talvez as fotografias que associam o rosto de Herberto Helder aos momentos mais tardios de sua vida e obra não sejam apenas prefigurações da morte. Talvez sejam também imagens de uma regressão do caráter mítico outrora atribuído ao poeta por sua própria poesia, em um movimento que se instila, paradoxalmente, no tempo detido das fotografias: tempo das paragens do tempo.

\section{PAUSA MUSICAL}

Mas as paragens do tempo não são exclusividade das fotografias. Na poesia tardia de Herberto Helder, elas se permitem pensar também em relação à música. Em Servidões (2013), ao antecipar o momento em que 
seria "interrompida a canção ininterrupta” (Helder, 2017, p. 669), o poeta dá ao tempo de sua morte o aspecto de uma pausa musical. Pouco antes, já quase no fim de A Faca Não Corta o Fogo (2008), a continuação da escrita se encontra com dificuldades ditas mais uma vez musicalmente: "mas não me lembra a música" (ibid., p. 598), escreve Herberto Helder, como quem situa a poesia em um lugar tão mais distante da memória quanto menos disponível a uma espécie de escuta, comparável à percepção musical.

E que tipo de escuta é este de que depende a poesia? Que música é esta de que é preciso lembrar? Para o poeta russo Alexandre Blok, trata-se de emanações sonoras, vibrações, fluxos energéticos vindos do caos, isto é, do próprio mundo em suas forças mais elementares, em estado de anarquia. Desta forma, segundo Blok, cabem ao poeta, por ordem, as seguintes tarefas: "premièrement, libérer les sons de lélément anarchique où ils son nés; deuxièmement, amener ces sons à l'harmonie, leur donner forme; troisièmement, porter cette harmonie au monde extérieur" (apud. Meschonnic, 1982, p. 97).

Nesta perspectiva, a poesia seria como um percurso, um movimento de organização, uma trama por que se distende e enforma certo rumor interno, pela qual circula uma corrente de energia que atravessa o poeta em algum ponto de um trajeto que leva dos sons disformes à harmonia musical, da escuta íntima à forma escrita, em sua exterioridade. Ou, em termos talvez um pouco mais herbertianos: da memória pessoal à montagem poética, das imagens amorfas à sequência poemática, da matéria bruta ao poema, coisa feita. A este fio condutor do caos aos cosmos, este contínuo entre o corpo e a linguagem, este gesto de recriação poética do mundo, Blok dá o nome de "ritmo".

\section{OS RITMOS}

Como prometido, estamos de volta ao tema do ritmo. Lembremos, então, a primeira parte do "Tríptico", de A Colher na Boca (1961). Escreve Herberto Helder, com Camões: "transforma-se o amador na coisa amada [...]” (Helder, 2017, p. 12). Neste mesmo poema, apenas algumas linhas à frente, "o amador e a coisa amada são um único grito" (ibid., p. 13). Quer dizer: o amador, o poeta, e a coisa amada, a poesia, estão em unidade: por eles circula uma mesma energia, há entre eles continuidade rítmica.

E, contudo, cinquenta e quatro anos mais tarde, o primeiro dos Poemas Canhotos (2015) repete: "coisa amada nas montanhas / amador no rés das águas" (Helder, 2015, p. 8-9). O poeta reitera a distância que o separa da poesia, sublinha a descontinuidade entre ele mesmo e sua escrita, insiste no intervalo entre seu corpo e o mundo. E o faz em redondilha maior. Portanto, já não no verso livre com que escreve, inscreve no poema, o ritmo de seu corpo.

Terão as inflexões tardias da poesia de Herberto Helder a forma de suas próprias alterações rítmicas? 


\section{CODA}

“[J]á não apanho o ritmo", escreveu Herberto Helder (2017, p. 676), em Servidões (2013). Em A Faca Não Corta o Fogo (2008), foi ainda mais explícito: "não sinto o ritmo, / estou separado, inexpugnável, incógnito, pouco, / ninguém me toca, / não toco" (ibid., p. 555). Talvez não se referisse simplesmente à solidão de seus últimos momentos ou às dificuldades tardias da escrita. Pode ser que falasse também de um descompasso entre sua intensidade e a do mundo em que afinal continuava seu poema. $\mathrm{Ou}$ das guinadas de sua escrita rumo a dicções novas e também impossíveis, porque destinadas a seu próprio fim. Ou pode ser ainda que o poeta acrescentasse à sua obra uma espécie de coda, que a orquestrasse em direção às suas cadências últimas, que acomodasse seu andamento à perspectiva de suas notas finais.

De todas as formas, falava da morte.

\section{REFERÊNCIAS BIBLIOGRÁFICAS}

BARTHES, Roland. A Câmara Clara - notas sobre a fotografia. Rio de Janeiro, Nova Fronteira, 1989.

BUESCU, Helena. Em Busca do Autor Perdido. Lisboa, Edições Cosmos, 1998.

FREITAS, Manuel de. Baixa biografia. Cão Celeste, no 4, p. 35-42, 2013.

GUSMÃO, Manuel. Tatuagem e Palimpsesto. Lisboa, Assírio \& Alvim, 2010.

HELDER, Herberto. Entrevista a Fernando Ribeiro de Mello. Jornal de Letras e Artes, $\quad \mathrm{n}^{\circ}$ 139, 17 de maio, s.p., 1964.

. Poemas Canhotos. Porto, Porto Editora, 2015.

. Letra Aberta, Porto, Porto Editora, 2016.

. Poemas Completos, Rio de Janeiro, Tinta da China, 2017.

. Photomaton \& Vox. Rio de Janeiro, Tinta da China, 2017a.

. em minúsculas, Porto, Porto Editora, 2018.

LISSOVSKY, Mauricio. Pausas do Destino - teoria, arte e história da fotografia. Rio de Janeiro, Mauad, 2004.

LOPES, Silvina Rodrigues. A Inocência do Devir. Lisboa, Vendaval, 2003.

MARIN, Louis: Écriture, images, gravures dans la représentation de soi chez Stendhal. In: CONTAT, Michel. L'Auteur et le manuscrit. Paris, PUF, p. 118-141, 1991. 
MARTELO, Rosa Maria. Em que língua escreve Herberto Helder?. Diacrítica. no 23/3, Braga, p. 151-168, 2009.

. Um lance último. Público (Ípsilon). 14 de junho, p. 9, 2013.

Acção, poema. Translocal no 2 - Lugar Lugares Herberto Helder, s.p., 2018.

MESCHONNIC, Henri. Critique du Rythme. Paris-Mesnil, Éditions Verdier, 1982.

SAID, Edward. Estilo Tardio. São Paulo, Companhia das Letras, 2009.

SERRA, Pedro. O céu a seu tempo. Instante de detenção, estilo tardio e metaplasmos em Luiza Neto Jorge. Comunicação apresentada ao seminário Estados de la investigación IV. Desarrollos teórico-metodológicos en los estúdios portugueses y brasileños, Universidade de Salamanca, 2018.

Recebido para publicação em 27/10/18

Aprovado em 10/01/19

\section{NOTAS}

1 Este ensaio foi desenvolvido no âmbito da Bolsa de Doutoramento (SFRH/ BD/136035/2018), financiada pela Fundação para a Ciência e Tecnologia, e no âmbito da investigação desenvolvida no grupo de Intermedialidades do Instituto de Literatura Comparada Margarida Losa (UID/ELT/00500/2019).

2 Doutorando em Estudos Literários, Culturais e Interartísticos pela Universidade do Porto. Investigador do Instituto de Literatura Comparada Margarida Losa. Mestre em Comunicação e Cultura pela Universidade Federal do Rio de Janeiro. Graduado em Comunicação Social por esta mesma instituição. Roteirista de cinema e televisão.

3 Este ensaio sucede a comunicação "As formas da morte: Herberto Helder, o estilo tardio e as intermedialidades", apresentada ao II Encontro de Jovens Pesquisadores em Literatura Comparada, na Faculdade de Letras da Universidade do Porto, em 14.09.2018. 